\title{
Research on the Fracture Resistance of Asphalt Mixture Based on Cohesion Zone Model
}

\author{
Wu Xirong \\ Key Laboratory of Highway Construction \& Maintenance Technique in Loess Region,
} Shanxi Provincial Research Institute of Communications, Taiyuan 030006, Shanxi;

Key words: asphalt mixtures; anti-cracking performance; evaluation method; fracture energy; J-integral; curvature strain energy

Abstract: Cohesion and crack opening displacement based on cohesive zone model were employed to evaluate the fracture resistance of asphalt mixture of SMA- $13 、 A C-13$ and CAM at $10^{\circ} \mathrm{C} 、 5^{\circ} \mathrm{C}$ 、 $0^{\circ} \mathrm{C} 、-5^{\circ} \mathrm{C} 、-10^{\circ} \mathrm{C}$. Using fracture toughness, cohesion and crack opening displacement index to analyze the crack resistance property of three kinds of asphalt mixture, the test results is that anti-cracking performance of SMA-13 is optimal, the second is AC - 13 and CAM. So, Fracture energy and cohesion model test can reasonably evaluate anti-cracking performance of asphalt mixture.

In order to evaluate crack resistance of asphalt mixture, the researchers have done a lot of experiments and research, so different test methods and evaluation indexes are put forward.

The test methods and evaluation indexes which are frequently used at home and abroad at present are mainly indirect tensile test, direct tensile test, low-temperature bending test, constraints temperature stress test specimens (frozen), the stress relaxation test, low temperature shrinkage coefficient test, a constrained beams of three point bending, $\mathrm{J}$-integral test, $\mathrm{C} *$ integral test, fatigue test, direct tensile fatigue, indirect tensile fatigue, low temperature bending creep test, direct tensile creep, the indirect tensile creep and uniaxial compression test, freeze-thaw cycling test and freeze-thaw splitting test ${ }^{[1-3]}$. But there is no accepted standard evaluation method.

In fact, based on different evaluation methods, performance of asphalt mixture at low temperature is not entirely consistent ${ }^{[4]}$. Different evaluation methods have their respective applicable scope. At present, the low temperature bending test is commonly used to evaluate the low temperature crack resistance of asphalt mixture,

However, the researcher point out that this method is difficult to fully reflect the mixture of the low temperature crack resistance and its evaluated result for modified asphalt mixture and Large porous asphalt mixture is incorrect ${ }^{[5]}$. Based on this reason, scholars put forward the energy evaluation index ${ }^{[6]}$. Another method commonly used is the low temperature bending creep test, which difficult to determine the stress level of modified asphalt mixture. HAO PeiWen and others think that $0^{\circ} \mathrm{C}$ compressive strain can be used as evaluation index at low temperature to evaluate anti-cracking performance of mixture. The method is simple easy to promote ${ }^{[7]}$.Others thinks, the critical stress intensity factor is an reasonable index of crack resistance, but this index used for evaluate crack resistance of viscoelastic material under a certain temperature is unreasonable and the $\mathbf{J}$ integral based on elastic-plastic mechanics theory more reasonable ${ }^{[8]}$;Dongre ${ }^{[9]}$ adapts bending beam test to evaluate the low temperature crack resistance of asphalt mixture and show that fracture toughness is more sensitive and more suited to evaluate crack resistance characteristics of asphalt mixture. Zhang dong think the bilinear CZM anti-cracking performance evaluation method is reasonable and comprehensive ${ }^{[10-11]}$. 
Based on the above research, $\mathrm{J}$ integral and double linear cohesion model used to study crack resistance of different structure asphalt mixture.

\section{Evaluation index}

\section{Cohesion model CZM}

Compared with the linear elastic fracture mechanics and elastoplastic fracture mechanics, the cohesion modelCZM is a kind of research method on crack failure and has been used to analyze the formation and extension of cracks in asphalt mixture. The crack interface cohesion and the relative displacement used to definite the model of cohesion The cohesion force and displacement relationship can be described by cohesion - displacement curve ${ }^{[10,11,12]}$, the curve ${ }^{[10]}$ is shown in fig 1 .

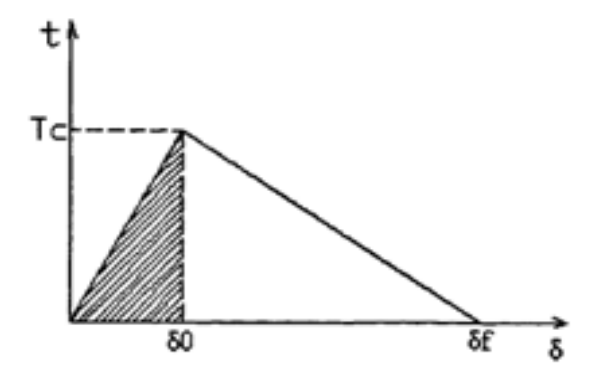

Fig 1 The curve of the bilinear $\mathrm{CZM}$

In fig $1, \delta_{f}$ - fracture plane maximum opening displacement, $T_{C}$ - tensile strength。

Using the fracture energy, tensile strength and opening displacement, coupled with curve, to evaluate the anti-cracking performance of asphalt mixture.

\section{Test methods}

\section{$J$ integral}

Specimen size of $\mathrm{J}$ integral test is $40 \mathrm{~mm} \times 250 \mathrm{~mm} \times 40 \mathrm{~mm}$, span $\mathrm{L}$ is $200 \mathrm{~mm}$, incision depth is $21.5 \mathrm{~mm}$, the test temperature is $10^{\circ} \mathrm{C}, 5^{\circ} \mathrm{C}$ and $0{ }^{\circ} \mathrm{C},-5^{\circ} \mathrm{C},-10^{\circ} \mathrm{C}$, and the loading rate is 1 $\mathrm{mm} / \mathrm{min}$.

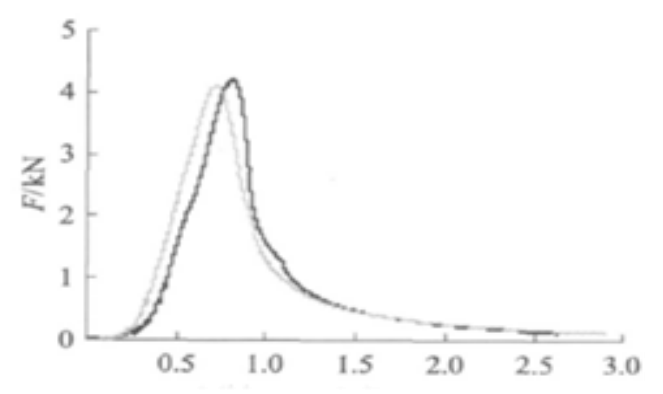

Fig 2 Load-deflection curve

Fracture can be calculated by the equation (1)

$$
G_{c}=\frac{U}{b\left(h_{0}-a\right)}
$$

Equation:

$\mathrm{U}$ is the area at the bottom of the deflection curve (fig 2 ), $\mathrm{J} ; \mathrm{b}$ is width of the beam, $\mathrm{m} ; h_{0}$ is height of the beam, m; a is kerf depth, m. Fracture toughness can be calculated by the equation (2) 


$$
J_{c}=\frac{\eta\left(U_{T}-U_{e}^{n c}\right)}{b\left(h_{0}-a\right)}
$$

Equation:

$\eta$ is a constant related to the size of the kerf width; $U_{T}$ is the area below the maximum load, $\mathrm{J}$; $U_{e}^{n c}$ is elastic energy stored in ductile zone, $\mathrm{J}$; When the cross ratio $\mathrm{L} / \mathrm{h}_{0}$ of the specimen is equal to 4, $U_{e}^{n c}$ can be ignored. This paper uses crack beam $\left(a / h_{0}=0.17\right)$, when evaluate the anti-crack performance, the value of $\eta$ will not affect the result, so $\eta$ will be assignment to 2.The bigger the critical fracture toughness is, the better crack resistance of asphalt mixture is ${ }^{[7,10]}$ 。

\section{Tensile strength test}

Compared to the indirect tensile test, the variability of bending test is smaller and permanent Deformation in the loading zone is small. So, semicircle bending test is suitable for evaluate the tensile properties of asphalt mixture.

The test instrument modified by MLS stabilization experiment apparatus The test temperature is at $10^{\circ} \mathrm{C}, 5^{\circ} \mathrm{C}$ and $0^{\circ} \mathrm{C},-5^{\circ} \mathrm{C},-10^{\circ} \mathrm{C}$ and the loading rate is $50 \mathrm{~mm} / \mathrm{min}$. The flexural tensile strength of specimens can be calculated by the equation (3).

$$
R=\frac{3 P L}{2 t h^{2}}=\frac{6 P L}{t D^{2}}
$$

Equation:

$\mathrm{P}$ - the largest load, $\mathrm{N}$;

$\mathrm{L}$ - distances between the supports, mm;

$\mathrm{h}$ - specimen height, $\mathrm{h}=\mathrm{D} / 2, \mathrm{~mm}$;

$\mathrm{t}$ - specimen thickness , mm;

$\mathrm{R}$ - tensile strength , $\mathrm{MPa}$;

$\mathrm{D}$-diameter of specimen, $\mathrm{mm}$ 。

\section{Cohesion model test}

The parameters of fracture and cracking strength can be determined by the test. The opening displacement can be calculated using formula(4). The curve of the bilinear CZM was draw using the above parameters。

$$
G_{C}=\frac{1}{2} T_{C}
$$

Among them, $G_{C}$ - fracture energy, $\delta_{f}$ - opening displacement, $T_{C}$ - strength of extension。

\section{Raw materials technical nature}

Asphalt is SBS modified asphalt. The aggregate is the different particle size of limestone rubble. The nature of mineral powder made from limestone grinding without aggregation is good. Mixture gradations are AC-13, SMA-13 and CAM. Mineral aggregate of three kinds of mixture gradation was optimal design. The results are shown in table 1.

Marshall volume design procedure was applied to mold specimen. The optimum asphalt content of asphalt mixture by Marshall is obtained. Different types of test specimen were tested and the results are shown in table 2. 
Table 1 mine ral aggregate gradation design

\begin{tabular}{cccccccccccc}
\hline \multirow{2}{*}{$\begin{array}{c}\text { sieve-pore } \\
\text { size }\end{array}$} & 16.0 & 13.2 & 9.5 & 4.75 & 2.36 & 1.18 & 0.60 & 0.30 & 0.15 & 0.075 \\
\cline { 2 - 10 } & 100.0 & 91.1 & 75.2 & 46.8 & 36.7 & 23.1 & 17.7 & 10.5 & 7.0 & 6.0 \\
AC-13 & 100.0 & 90.0 & 70.5 & 33.1 & 23.9 & 19.2 & 17.3 & 14.9 & 13.5 & 12.5 \\
SMA-13 & 100.0 & 95.0 & 87.0 & 74.0 & 57.0 & 0.0 & 26.0 & 14.0 & 6.0 & 5.0 \\
CAM & 10.0 &
\end{tabular}

Table 2 different structure types of mixture volume parameter test results

\begin{tabular}{cccc}
\hline mixture type & $\begin{array}{c}\text { Asphalt } \\
\text { content } \\
/ \%\end{array}$ & $\begin{array}{c}\text { Bulk } \\
\text { density } \\
/ \mathrm{g} . \mathrm{cm}^{-3}\end{array}$ & $\begin{array}{c}\text { Void } \\
\text { fraction } \\
/ \%\end{array}$ \\
\hline AC-13 & 4.9 & 2.466 & 3.4 \\
SMA-13 & 5.4 & 2.510 & 3.4 \\
CAM & 5.8 & 2.417 & 3.6 \\
\hline
\end{tabular}

\section{Test results and analysis}

Test results and analysis based on cohesion model

The result of rupture and tensile strength under different temperature was got by test. Opening displacement can be calculated by type (4). The test result is shown in fig 3-fig7.

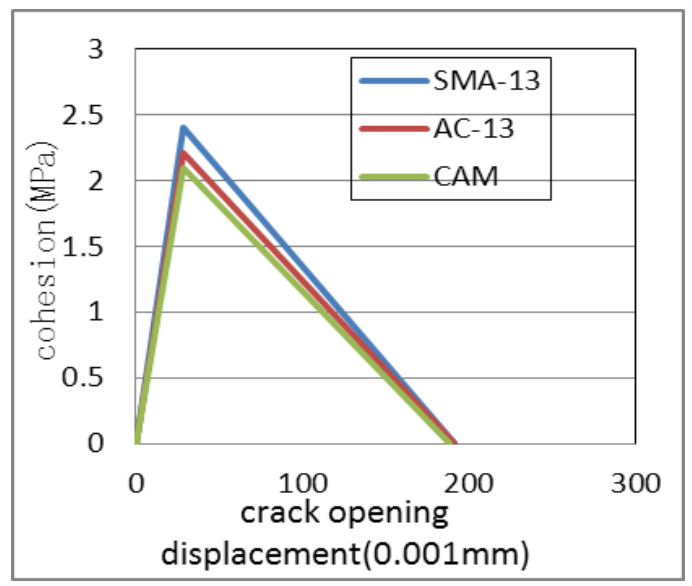

Fig 3. $10^{\circ} \mathrm{C} t-\delta$ curve of different types of asphalt mixture

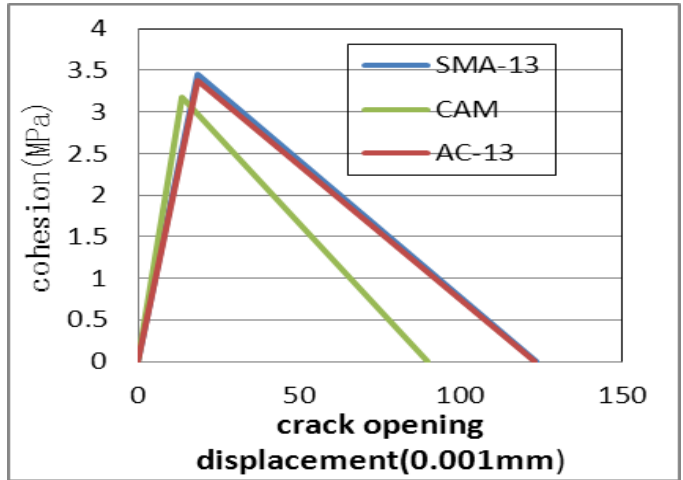

Fig 4. $5^{\circ} \mathrm{C} t-\delta$ curve of different ty pes of asphalt mixture 


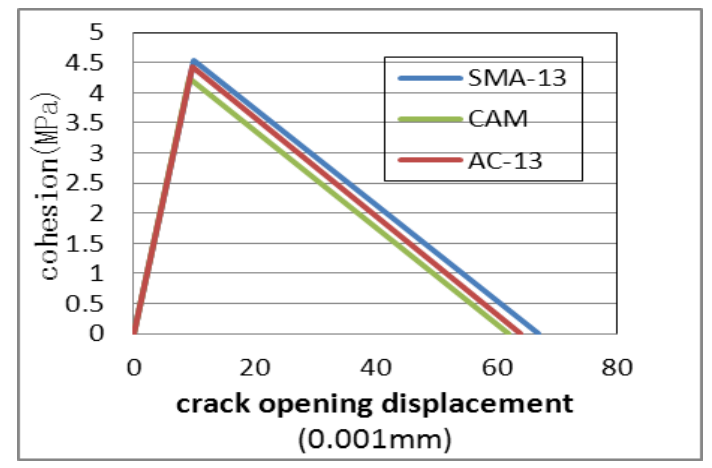

Fig 5. $\quad 0^{\circ} \mathrm{C} t-\delta$ curve of different types of asphalt mixture

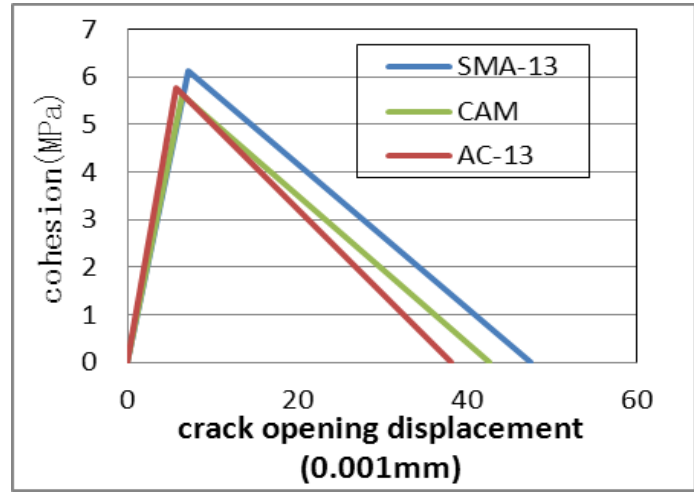

Fig 6. $-5^{\circ} \mathrm{C} t-\delta$ curve of different types of asphalt mixture

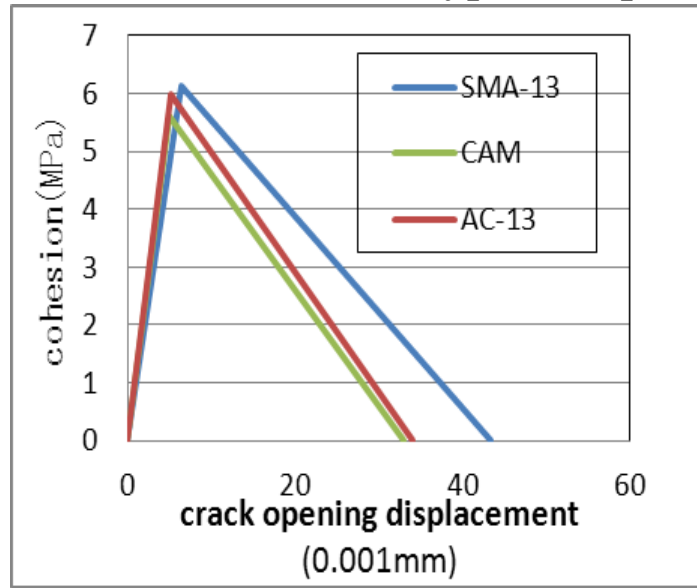

Fig 7. $-10^{\circ} \mathrm{C} t-\delta$ curve of different types of asphalt mixture

Fig 3 to fig 7 is the curves of different types of asphalt mixture, the figure shows:

(1) Fracture energy, tensile strength and crack formed opening displacement value of SMA-13 is greater than AC-13 and CAM;(2) Compared the SMA-13 to AC-13 type asphalt mixture in $-10{ }^{\circ} \mathrm{C}$, the fracture energy of SMA-13 is 1.31 times than fracture energy of the AC-13. Crack opening displacement of SMA-13 is 1.27 times than crack opening displacement of the $\mathrm{AC}-13 ;(3)$ Compared AC - 13 to CAM type asphalt mixture.in $-10^{\circ} \mathrm{C}$. Fracture energy of AC-13 is 1.10 times than fracture energy of CAM. The crack opening displacement of AC-13 is 1.03 times than crack opening displacement of CAM.

In addition, the regularity of crack displacement of three kinds of asphalt mixture showed the same: the crack opening displacement increases gradually as temperature increases. The three kinds of asphalt mixture of opening displacement close to $2 \mathrm{~mm}$ or so. From the test result we can think over this temperature, asphalt pavement not easy to produce cracks. So the asphalt surface cracks is 
mainly formed under low temperature conditions. According to test data, the fig8 was draw which shows the fracture energy of the same kind of asphalt mixture under different temperature conditions.

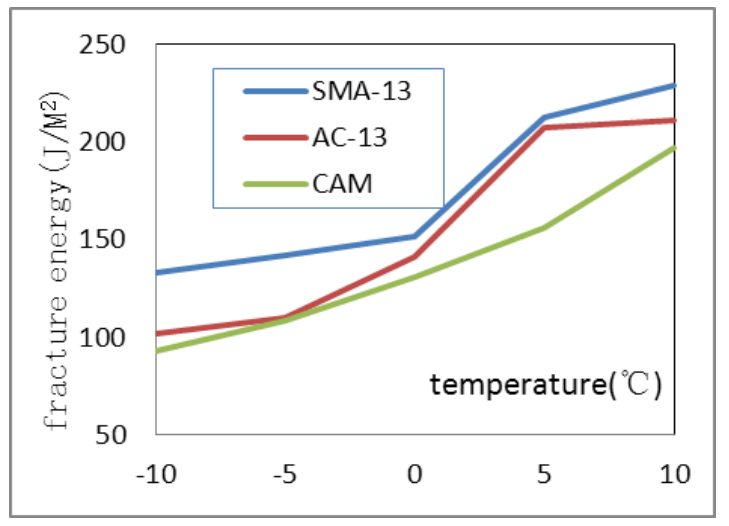

Fig 8 fracture energy of three kind of mixtures under different temperature

We can see from the result of fig8 that three kinds of asphalt mixture showed the same pattern: with the increasing of temperature, the fracture of asphalt mixture can significantly increase. With the temperature rising from $-10^{\circ} \mathrm{C}$ to $10^{\circ} \mathrm{C}$, SMA- 13 fracture can be increased by $72 \%$ and $\mathrm{AC}-13$ fracture can be increased by about 2 times. Thus, when the temperature rises, the crack resistance of asphalt mixture performance is greatly improved, especially when the temperature is greater than $0^{\circ} \mathrm{C}$, the crack resistance increased faster, therefore, the lower the temperature, the more easy of asphalt pavement produce crack.

\section{Conclusions}

Results show under different temperature conditions, the crack resistance of SMA-13 is optimal.With increasing of temperatures, anti-cracking performance of asphalt mixture greatly improved, especially the temperature is greater than $0{ }^{\circ} \mathrm{C}$ and the crack resistance increased faster, therefore, the lower the temperature, the more easy to produce cracks of asphalt pavement.

\section{References}

[1] Liu Tao, Hao Peiwen. Research on appraisal method of low temperature crack resistance for asphalt mixture $[\mathrm{J}]$. Journal of tongji university (natural science edition), 2002, 30 (12): 1468-1471.

[2] Li Feng, Zeng Wei, Shi Xiaopei. Evaluation on the crack resistance and influence factors at low temperature of asphalt mixture $[\mathrm{J}]$. Journal of Shandong construction university, 2012, 27 (6): 555-559.

[3] Xu Haojun. Study on Drought alpine region Asphalt mixture Crack resistance at low temperature. Master's degree thesis. Chang'an university.2008.

[4] Zhang Hong. Evaluation methods of asphalt-mixture's anti-cracking performance at low temperature $[\mathrm{J}]$.Journal of Chang'an University: Natural Science, 2002, 22( 4) :5-8.

[5] Wang Gang,Wang Binggang,Ma Biao.Comprehensive evolution method for anti-cracking performance of ATB [J].Highway,2008(4):55-59.

[6] GeZhesheng, Huang XiaomingXu-Guoguang. Evaluation

of-asphalt- mixture's- low-temperature-anti-cracking-performance by curvature strain energy 
method [J]. Journal of Southeast University:NaturaScience,2002,32(4):653-655.

[7] Hao Peiwen,Zhang Dengliang,Hu Xining. Evaluation- method for low temperature anti-cracking performance of asphalt mixture $[\mathrm{J}]$.Journal of Xi'an Highway University,2000,20(3):1-4.

[8] Liu Jinghui, Wang Duan-yi, Liu Yu. Evaluation of the fracture resistance of asphalt mixture using the J-integral.

[9] Dongre R, M G Sharma, DA Anderson. Development of fracture criterion for asphalt mixes at low temperatures $[\mathrm{J}]$. In Transportation Research Record :Journal of the Transportation Research Board ,No.1228 , TRB, National Research Council , Washing ton, D.C, 1989 :94-105.

[10] Zhang Dong, Huang Xiaoming, Zhao Yongli.Comparative

Study-on-the-Evaluation- method-of-the-Fracture-Resistance of Asphalt Mixtures $[\mathrm{J}]$ Journal of building materials. 2012,15(2):222-226.

[11] Zhang Dong. Research on fracture of asphalt pavements based on cohesive zone mode [D]. Nanjing:School of Transportation,Southeast University,2010.

[12] Zhao Yongli, Zhang Dong. Study of Low Temperature Cracking of Asphalt Pavement Based on Cohesive Zone Model [J]. Journal of Highway and Transportation Research and Development, 2010, 27 (1): 11-15. 